\title{
Was lange währt, wird endlich gut! Oder: «Mitenand goht's besser»
}

Nach einer langen Zeit der Ungewissheit und intensiver Verhandlungen konnte ein Meilenstein in der TARMEDGeschichte gesetzt werden. Die Revision eines TARMEDKapitels steht vor der Vollendung.

Das Leitungsgremium TARMED Suisse hat am 18. April 2007 den Schlussbericht des Reengineering III genehmigt und zuhanden des Bundesrates verabschiedet. Das Gelingen des Projektes hängt somit nur noch vom Entscheid des Bundesrates ab.

Wie kam es doch noch zu einer für alle Beteiligten guten Lösung von RE III «Bildgebende Verfahren»? Nachdem Ende 2006 - aufgrund des Dissensantrages der FMH unter den Partnern von TARMED Suisse keine Lösung gefunden werden konnte, wurden die Arbeiten im Februar 2007 nach dem «Runden Tisch» beim BAG unter der Führung der FMH wiederaufgenommen.

FMH-intern wurde gemeinsam nach Lösungen gesucht und wurden diese miteinander entwickelt. Die Zusammenarbeit zwischen SGUM, KHM, Radiologen und dem Tarifdienst der FMH war vorbildlich. Dank des gemeinsamen, geschlossen starken Auftretens wurde eine Konsenslösung erst möglich gemacht. Die Überführung des Kapitels 30 in die jetzige Form des Kapitels 39 ist für alle Fachgruppen nachvollziehbar und zufriedenstellend ausgefallen.

Auch die Zusammenarbeit mit $\mathrm{H}+$ und den Kostenträgern war von gegenseitigem Respekt, die Verhandlungen mit den Kostenträgern (santésuisse, UV/IV/MV) aber auch von harten Verhandlungspositionen geprägt. Es konnte dank des gemeinsamen Willens für eine Konsenslösung konstruktiv gearbeitet werden. Dieses Bestreben hat dann zum positiven Schlussresultat geführt.

Ich hoffe, dass die schliesslich konstruktive und konsensuelle Bewältigung der aufgetretenen Probleme für die Zukunft wegweisend sein wird. Wir werden konkret und detailliert über die Resultate berichten, sobald eine Genehmigung durch den Bundesrat vorliegt. Liegt die Genehmigung vor, wird das Kapitel 39 (RE III «Bildgebende Verfahren») auf den 1. Januar 2008 eingeführt.

Damit ist es erstmals in der Geschichte des TARMEDTarifs gelungen, ein Kapitel zu revidieren und den aktuellen Gegebenheiten anzupassen.

Herzlichen Dank allen Direktbeteiligten für den grossartigen Einsatz - der erst eine Lösung in so kurzer Zeit möglich gemacht hat - und die angenehme und gute $\mathrm{Zu}-$ sammenarbeit.

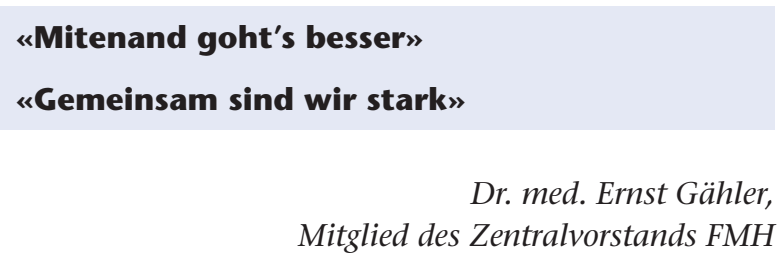

